\title{
Correction to: Benthic primary production and respiration of shallow rocky habitats: a case study from South Bay (Doumer Island, Western Antarctic Peninsula)
}

\author{
Lorenzo Rovelli ${ }^{1,5}$ (1) $\cdot$ Karl M. Attard ${ }^{1,2} \cdot$ César A. Cárdenas $^{3} \cdot$ Ronnie N. Glud $^{1,4}$
}

Published online: 29 July 2019

(c) Springer-Verlag GmbH Germany, part of Springer Nature 2019

\section{Correction to: Polar Biology https://doi.org/10.1007/s00300-019-02533-0}

The article was published with erroneous values in Table 1 . While the corrections were forwarded by the authors for typesetting, manual tinkering to the layout style was needed to achieve the desired presentation of the table. The author group and the publisher apologize for the previous erroneous presentation of this information. This correction stands to support the corrections made. The original article has been corrected.

The original article can be found online at https://doi.org/10.1007/ s00300-019-02533-0.

Lorenzo Rovelli

lorenzo@biology.sdu.dk

1 Nordcee, Department of Biology, University of Southern Denmark, 5230 Odense M, Denmark

2 Tvärminne Zoological Station, University of Helsinki, 10900 Hanko, Finland

3 Departamento Científico, Instituto Antártico Chileno, 6200965 Punta Arenas, Chile

4 Department of Ocean and Environmental Sciences, Tokyo University of Marine Science and Technology, Tokyo 108-8477, Japan

5 Present Address: Institute for Environmental Sciences, University of Koblenz-Landau, Landau, Germany 
Publisher's Note Springer Nature remains neutral with regard to jurisdictional claims in published maps and institutional affiliations. 